\title{
Psicanálise na Educação Médica: Subjetividades Integradas à Prática
}

\author{
Psychoanalysis in Medical Education: \\ Subjectivity Integrated into Practice
}

\author{
Sandra Gehling Bertoldi ${ }^{I}$ \\ Maria Nestrovski Folberg \\ Waldomiro Carlos Manfroi ${ }^{\text {III }}$
}

\section{PALAVRAS-CHAVE: \\ - Educação Médica; \\ - Psicologia Médica; \\ - Psicanálise; \\ - Transferência; \\ - Humanização.}

Recebido em: 16/10/2012

Reencaminhado em: 26/01/2013

Aprovado em: 19/03/2013

REVISTA BRASILEIRA DE EDUCAÇÃO MÉDICA $202 \frac{202}{37(2): 202-209 ; 2013}$
${ }^{I}$ Universidade Federal de Pelotas, Pelotas, RS, Brasil.

"Universidade Federal do Rio Grande do Sul, Porto Alegre, RS, Brasil.

III Universidade Federal do Rio Grande do Sul, Porto Alegre, RS, Brasil; Academia Sul-Rio-Grandense de Medicina, Porto Alegre, RS, Brasil. 


\section{INTRODUÇÃO}

Este trabalho situa-se na intersecção Psicanálise e Formação de Médicos, analisando a contribuição do método psicanalítico na Faculdade de Medicina da Universidade Federal de Pelotas, onde o Projeto Abuchaim/Zimmerman ${ }^{1}$ instituiu a psicologia médica alicerçada na psicanálise ${ }^{(2)}$, participando da formação continuada de cerca de quatro mil médicos desde sua implantação.

A lei universal de interdição ao incesto, que é mítica, funda nossa condição de seres da cultura, com uma renúncia ao excesso de gozo, e impõe-se sem estar escrita em lugar algum, delimitando todos os agrupamentos sociais humanos. A origem e a transmissão dessa lei se dão pela linguagem, pela inscrição no inconsciente de formações da cultura. O preço a pagar pela condição humana torna-se uma dívida simbólica que assumimos com nossos antepassados e com a coletividade a que pertencemos, seja ela representada pela cultura, pelo país ou pela classe social.

Levantam-se questões: Como se constitui o médico na contemporaneidade? Como fica o sujeito que faz medicina diante das demandas do corpo social, com a excelência a ser alcançada pela ciência médica e o enfrentamento do mercado e das pressões exercidas pela indústria?

Quando ensinou a importância de conhecer e manejar a transferência ${ }^{2}$ para atender pacientes, Freud ${ }^{3}$ implantou propósitos para uma educação médica preocupada com o atendimento das subjetividades humanas, tanto no paciente como no médico.

Assim, tem-se que estudantes de medicina correm riscos. A evolução da ciência médica responde a demandas crescentes, acarretando altos custos para quem se encontra na linha de frente. Jovens chegam às faculdades de medicina com extensa bagagem, pressionados por ideais sociais enlaçados a suas singularidades, mas com um importante caminho a ser trilhado junto a seus professores. Os médicos são convocados para atender sofrimento e morte e, nesse sentido, há uma busca contínua pela excelência promovendo avanços constantes, ainda que envolva riscos. Qual é, então, o lugar reservado ao médico na sociedade atual?

\section{PSICANÁLISE E EDUCAÇ̃̃o MÉDICA}

Freud $^{3}$ discutiu o valor da psicanálise para a formação de médicos e cientistas, destacando que as faculdades dirigiam o estudante para os campos da anatomia, da física e da química, falhando no esclarecimento do significado dos fatores mentais, bem como nas doenças e seu tratamento. Os cursos de psicologia médica surgiram como tentativas de resposta a deficiências no currículo universitário. Em suas considerações, Freud ponderou que o estudante de medicina jamais aprende- ria a psicanálise propriamente dita, mas salientou que,para os objetivos pretendidos, seria suficiente que o aluno aprendesse algo a partir da psicanálise.

Assumindo o inconsciente freudiano não apenas como o que escapa à consciência, mas como o lugar onde se faz reconhecer um desejo ignorado pelo locutor, pode-se mostrar uma relação com a verdade do próprio sujeito. $\mathrm{O}$ inconsciente fala de acordo com sua própria gramática e lógica. Para Lacan ${ }^{4}$, é disso que Freud fala quando diz: "Wo Es War, soll Ich werden" ("Onde isso estava, eu devo advir"), ou seja, "Eu deveria ousar me aproximar do lugar de minha verdade".

Os professores não transmitem atitudes magicamente aos estudantes: é preciso que haja intenção nessas atitudes, e que se instaurem cenários de ensino-aprendizagem como dispositivos adequados ao desenvolvimento de competências.

Muniz e Chazan ${ }^{5}$, Zaidhaft ${ }^{6}$, Nogueira-Martins ${ }^{7}$ e outros autores têm estudado o ensino da psicologia médica no sentido de ampliar as habilidades e competências médicas em comunicação e relação com os pacientes. Gauer et al. ${ }^{8}$ descrevem dificuldades encontradas por profissionais de saúde para cuidarem de si e estratégias para proporcionar apoio.

Os grupos Balint ${ }^{9}$, introduzidos pelo psicanalista húngaro de mesmo nome, baseavam-se no vínculo estabelecido entre profissional e paciente e suas aplicações para o aprendizado, a partir de casos-problemas. Eksterman ${ }^{10}$ escreve sobre a medicina psicossomática no Brasil, veiculando à psicanálise a tradução do mundo simbólico como essência do existir humano. Para Balint, o melhor remédio para o paciente seria a própria pessoa do médico, apontando para a importância da prática médica e as implicações transferenciais daí decorrentes.

Souza ${ }^{11}$ associa pesquisa no campo da psicanálise à experiência pedagógica na formação médica. A pesquisadora defrontou-se com incertezas, enigmas e limites do conhecimento médico, legitimando a pertinência da dúvida e do questionamento no espaço da prática médica, e Cohen ${ }^{12}$ investiga a problemática do fracasso escolar, na intersecção Psicanálise e Educação em um espaço interdisciplinar, e salienta o singular do fracasso em uma lógica contingente, incluindo o real, isto é, o impossível, o ineducável.

Ao buscar atendimento, o paciente supõe que o médico possua o saber suficiente para livrá-lo de seu sofrimento. Assim fundamenta-se o nascimento da transferência, na definição freudiana de relações emocionais com o médico, de caráter afetuoso ou hostil, que se derivam das relações infantis com os pais e não se baseiam na situação real atual da vivência do paciente.

Lacan $^{13}$, ao fundamentar os fenômenos transferenciais, destaca o saber suposto e o valor de verdade do sintoma. 
Como "sujeito suposto saber", o psicanalista/médico/terapeuta é colocado, pelo paciente envolvido no tratamento, como aquele que conhece suas respostas, seus segredos, havendo assim o reconhecimento de outro sentido, inconsciente, para os seus atos. Da mesma forma, o professor é colocado no lugar do saber, estabelecendo condições para a transferência professor-aluno, possibilitando uma relação que sustenta o surgimento do desejo de aprender.

Folberg ${ }^{14}$ diz que a educação pode apoiar-se e construir-se como uma projeção do que se pretende ser o resgate do saber não sabido e como possibilidade de sacudir o interior de cada um, ao provocar deslocamentos e reverberações das palavras lançadas, intencionadas, endereçadas e depositadas propositalmente, criando a pluralidade de sentidos.

A extensão universitária configura-se em um papel importante na formação médica, não apenas por concretizar uma interação com a sociedade, mas por permitir a construção do conhecimento advindo do contato direto com ela, sendo ainda a atividade em que interagem professor-aluno-comunidade, estabelecendo cenários de aprendizagem e produção de conhecimentos ${ }^{15}$. Através de atividades de extensão, pode-se favorecer conscientização crítica, criando condições para que a formação não fique restrita a aspectos técnicos, integrando-se à rede assistencial e ao papel socialmente demandado de humanização, sensibilização, percepção de necessidades sociais, trabalho em equipes multidisciplinares e desenvolvimento de competências.

Manfroi ${ }^{16}$ salienta a importância da qualificação do corpo docente e a produção de conhecimentos em educação e saúde para o sucesso de mudanças curriculares propostas e em andamento na área da saúde.

Demandas sociais à humanização nos grupos científicos encontraram algumas respostas através da definição de parâmetros pela Política Nacional de Humanização-(PNH) ${ }^{17}$, com a responsabilização e participação de todos os envolvidos no processo saúde-doença, reconhecendo diversidades e vulnerabilidades dos sujeitos envolvidos.

A Capes ${ }^{18}$, por sua vez, criou uma nova área de pesquisa, chamada Área Multidisciplinar, voltada à adoção de atitudes interdisciplinares e humanistas, colocadas como possibilidades enriquecedoras e ampliadoras da ciência. Essa área representa o reconhecimento do desafio imposto na formação de alunos, docentes e pesquisadores diante das várias formas de produção de conhecimento propostas no mundo contemporâneo e do enfrentamento das novas perspectivas teórico-metodológicas de pesquisa ${ }^{16}$. Deslandes e Mitre ${ }^{19}$ chamam atenção para o fato de que o conceito de humanização enfrenta certo processo de banalização dos desafios que anuncia e, consequentemente, o risco de esvaziamento. Além de estar integrada à prática, a essência da formação humanística é seu caráter transversal ${ }^{20}$.

\section{PSICOLOGIA MÉDICA NA LEIGA}

A Faculdade de Medicina da Universidade Federal de Pelotas foi fundada como uma instituição particular e, como ainda não pertencia a nenhuma universidade - federal ou católica -, ganhou o apelido que é sua marca, e pelo qual alunos, professores, ex-alunos, pacientes e comunidade a reconhecem até hoje. No entanto, vale lembrar que a palavra "Leiga" tem como definição aquele que é laico, não clérigo; ou ainda, o que é estranho ou alheio a um assunto, desconhecedor. O sentido conotativo de "Leiga", simplesmente considerado como atributo da prática da ciência médica, poderia sugerir uma indicação contrária aos ímpetos de um médico? Pode-se questionar, então: como se manteve esse nome, orgulhosamente citado por seus "filhos", em sites, fotos, festas, cartazes, formaturas, nas reuniões acadêmicas e mesmo em reuniões de conselhos diretivos, com conotação carinhosa, sem diminuir a qualificação e a competência profissional dos médicos da Leiga, até mesmo ao contrário. Levanto a hipótese que essa peculiaridade da faculdade situe-se entre suas especificidades, com uma estrutura de ensino com características especiais. Pode-se supor que "Leiga" sustente-se como um nome que ocupe um lugar simbólico, ligado aos princípios ético-humanistas que fundamentam a estruturação curricular da faculdade.

Para Lacan ${ }^{13}$, o inconsciente se estrutura como uma linguagem. O significante denominado Nome-do-Pai é a imposição simbólica de um Nome que articula uma linhagem, uma narrativa, uma história - trata-se do Nome que antecipa, ordena e perpetua a existência de alguém.

Este estudo, portanto, estruturou narrativas em busca de sentidos pelo enfoque do inconsciente, sem perder de vista que a psicologia médica está inserida no compromisso curricular de uma escola médica, visando a atender às necessidades básicas de saúde (NBS) da população, "na graduação de conferir formação geral e competências básicas ao médico para inserir-se no mercado de trabalho tão logo receba o diploma"21.

O modelo de ensino idealizado pelos professores e psicanalistas Darcy Abuchaim e David Zimmermann baseou-se no acompanhamento longitudinal do aluno ao longo do curso médico e em sua inserção precoce em atividades práticas e discussão em pequenos grupos, tendo a teoria psicanalítica como base de fundamentação. A metodologia de ensino escolhida foi a problematização $o^{22,23}$, a partir das questões vivenciadas pelos alunos em suas diversas práticas com pacientes, familiares ou com as equipes de saúde às quais estão integrados. 
A criação do programa teve como objetivo preparar médicos para o atendimento integral do paciente. "O aluno tem de adquirir experiência e habilidade de falar com pessoas, de ouvir histórias e de acelerar, através de vivências diversas, seu desenvolvimento emocional"1 (p.13).

Ainda assim, muitas dificuldades costumam ser enfrentadas. Eizirik ${ }^{24}$ compara a tarefa de professores e alunos de psicologia médica com a de Sísifo, no que diz respeito à resistência e ao desafio, aspectos que se reiniciam a cada semestre. Ele diz: “Não queremos ensinar e eles não querem aprender" 24 (p.134).

O desenvolvimento acentuado da psicofarmacologia, a expansão científica da psiquiatria e a possibilidade de renovação no quadro de professores colocam-se como preocupações e ameaças à continuidade do Programa, na medida em que trabalham com paradigmas que tentam excluir a subjetividade.

$\mathrm{O}$ momento em que o aluno começa a se colocar diante do paciente, executando um ato em que é percebido como médico,torna-se marcante na sua formação, capaz de estabelecer crises e marcar seu futuro profissional. Assumir essa posição, que é caracterizada pela transferência, apresenta-se a ele como uma tarefa carregada de dificuldades, riscos e desafios. Trata-se de um momento especialmente difícil do curso.

\section{EXTENSÃO E PESQUISA EM RELAÇÃO MÉDICO- PACIENTE $^{25}$}

A partir de 1997 foi criado o Projeto de Extensão em Relação Médico-Paciente, visando a ampliar a possibilidade de comunicação e desenvolvimento de competências e habilidades dos alunos com os pacientes. Seguindo o desafio de incorporar a subjetividade e os questionamentos da psicanálise à prática de jovens graduandos em medicina, esse projeto desenvolve uma monitoria semanal com alunos que iniciam a prática semiológica. Pequenos grupos de três alunos reúnem-se com um monitor para a anamnese e exame físico de um paciente, fazendo depois uma reunião para a discussão das dificuldades, conquistas e sentimentos vivenciados. Os monitores e os coordenadores do projeto reúnem-se semanalmente para debater as dificuldades a partir da leitura dos relatórios da atividade realizada pelos pequenos grupos. $\mathrm{O}$ aluno, como monitor, tem a oportunidade de desempenhar dois papéis: o de aluno e o de ensinante. Os fenômenos surgidos, dessa forma, permitem diversas abordagens da transferência e do desejo de saber, e esses papéis devem ser trabalhados no grupo realizado semanalmente.

A monitoria promove uma prática compartilhada ao jovem aluno, para que possa se posicionar diante do paciente, além de propiciar a todo grupo a oportunidade de falar a respeito das angústias surgidas durante o atendimento. Os grupos pequenos facilitam a intimidade e ajudam a quebrar exigências idealizadas do grande saber exigido ao médico.

Os pacientes, ao agirem/reagirem aos tropeços da doença ou da própria inexperiência dos alunos, ensinam e possibilitam reflexões sobre as angústias vividas. A partir daí, criam-se possibilidades de novas escritas, em busca de sentidos e competências.

Constantes desafios são enfrentados a cada semestre na execução da tarefa. Reconhecer e enfrentar as resistências, quando a demanda é outra, torna-se parte da construção invisível da psicanálise, na medida em que o inconsciente permeia e constitui o sujeito.

Não se cria a ilusão de que os problemas são ou estão resolvidos. As resistências são comuns e aparecem em expressões do tipo: "A Psico é uma viagem!", "Nós temos aula de Psico demais", “Não entendo o porquê dessas aulas!”. É preciso manter a posição de não detentor do saber, suportando o desconforto de estar em "outra cena", para não atender às demandas de colocar ordem, buscando referências na ética do desejo e mantendo constantes as indagações, tensões e inquie$\operatorname{tações~}^{26}$.

\section{METODOLOGIA DE PESQUISA}

Toda a hipótese deve suportar ser interrogada. Assim, desenvolvemos uma pesquisa cujo caminho metodológico apontou para uma abordagem qualitativa, aprovada pelo Comitê de Ética em Pesquisa, por meio do Of. no 100/09,CAAE 12652413.5.0000.5317, inscrito na Plataforma Brasil sob número 002924/2013, seguindo os preceitos da Resolução 196/96 do Ministério da Saúde ${ }^{27}$. O processo buscou compreender o espaço ocupado pelo método psicanalítico na formação de médicos na UFPEL, sua configuração como saber e seu papel no desejo de aprender.

Adotou-se a modalidade de estudo de caso, por essa técnica de pesquisa admitir uma análise mais profunda e abrangente das situações estudadas e pela necessidade de se buscar uma ampla abordagem da realidade vivenciada, inserida em um contexto ${ }^{28,29}$.

Para a coleta dos dados, foram realizados grupos focais durante o segundo semestre letivo de 2009. Como amostra, foram selecionados os alunos do projeto de extensão Relação Médico-Paciente em Estudantes de Medicina, em três grupos. Foram considerados representativos pela possibilidade demonstrada para o aprofundamento das múltiplas dimensões do objeto de estudo e por serem heterogêneos quanto à etapa do curso. Foram feitas reuniões no início, no meio e no final do semestre. Todas as reuniões foram gravadas, com o devido consentimento dos sujeitos envolvidos, e o registro contou 
com as transcrições das gravações de voz a respeito das falas e das atitudes dos sujeitos, isto é, dando atenção aos significantes, sinalizando interrupções, suspensões, hesitações, gestos, entonações, com o intuito de capturar sinais sutis fundamentais da produção do sujeito para as conclusões do estudo ${ }^{30}$.

A análise dos dados seguiu pressupostos psicanalíticos, de acordo com as concepções da enunciação. Nessa concepção ocorre a projeção de conflitos por meio de palavras, silêncios e lacunas, indicando processos geralmente inconscientes ${ }^{30}$.

\section{RESULTADOS E DISCUSSÃO}

Encontramos no discurso do grupo a busca de um saber ilimitado, idealizado e exigente, que ultrapassa os conhecimentos possíveis e corresponde a uma figura mítica do médico. Schüller ${ }^{31}$ ensina que o mito é palavra de verdade nos contos homéricos, e para conhecer o homem tem que se ir à verdade do mito, pois lá se manifestam as concepções humanas. $\mathrm{O}$ mito confere uma fórmula discursiva a alguma coisa que não consegue ser transmitida em sua definição de verdade.

Nesse sentido, foram reveladas pelo grupo estudado exigências de um saber ilimitado e inúmeras expectativas também grandiosas, advindas de figuras representativas como mãe, pai, namorado(a), colegas e da sociedade em geral. Parecem traçar um perfil do "médico ideal", diante do qual se colocam frustrados, ansiosos e inquietos. Eis algumas falas que demonstram isso:

“Quero ser médica, mas também quero ter qualidade de vida,
quero ficar com minha família." (BA)
"É que somos muito cobrados. Na sociedade também, né? Ah,
é médico. Médico tem que saber tudo. Se não sabe..." (GF)
"A pessoa te pergunta o que você estuda. Tu falas: Medicina.
Nossa!! Medicina, vocêé inteligente! Que orgulho, hein!" (VD)

"Minha mãe ligou, falando que meu avô tava com caxumba. Eu tinha que saber tudo de caxumba." (HA)

“É. Na família do meu namorado, cada semana uma pessoa tá doente, né? E daí me pergunta: ah, o médico falou isso. Deu tal remédio, o que tu achas? E vou saber?! (risos)." (NB)

As exigências do estudante de medicina quanto à aquisição de competências e saberes são percebidas como advindas de um outro, lugar simbólico onde a consciência não tem acesso. Através de uma demanda deste outro, articula-se, na psicanálise, o sujeito na linguagem, dividido em sua verdade e saber.
O ideal de ego pode ser mantido como ponto de identificação simbólica e representar um suporte ético para o desejo de aprender. Pode sustentar os grandes esforços, dedicação e empenho reclamados durante a formação e mesmo depois, pela excelência que é exigida por qualquer pessoa que busca atendimento médico. A inconstância do saber científico, no entanto, exige estudos permanentes, e a arrogância seria a única possibilidade de sentir-se completo e totalmente em dia com o conhecimento.

Lacan $^{32}$, ao situar a origem de seu ensino nos primeiros livros de Freud, chama atenção para os chistes, tropeços da fala, furos no discurso, trocadilhos, jogos de palavras e equívocos abordados servindo de apoio às descobertas sobre o que se trata na experiência psicanalítica, e convida para a análise das palavras, não pelo que significam, e sim para seu cruzamento em uma rede associativa, a partir da qual surgirá o ponto-núcleo, o centro de gravidade do desejo.

Ao mesmo tempo em que o grupo estudado apresenta suas expectativas e as idealizações de um saber impossível ao médico (míticas e advindas do outro) introduz, através do humor e da ironia, a capacidade de um reconhecimento ético de suas limitações, possibilitando a manifestação do desejo de "ter sua família e qualidade de vida".

Lacan $^{4}$ sublinha a correlação da ignorância com o saber, referindo-se à douta ignorância, conceito de Nicolau de Cusa, como um saber elevado, um requisito aos médicos que intentam fazer dela um saber estabelecido.

Pesquisadores chamam atenção para a necessidade de controlar as observações, viabilizando-as à comunidade científica. Estudiosos de diferentes áreas, entretanto, declaram que muitas situações específicas de pesquisa puderam ser realmente consideradas não durante a observação, mas "só depois" ou a posteriori, o que na definição freudiana do Nachträglichkeit é designado como um processo de reorganização ou reinscrição, pelo qual os acontecimentos traumáticos adquirem significação para o sujeito apenas em um contexto histórico e subjetivo posterior, que lhes confere uma nova significação ${ }^{33}$. A lógica que sustenta o método psicanalítico confia em uma escuta flutuante e na associação livre, e assim descobre um sujeito dividido em verdade e saber. O dito espirituoso é uma das formações do inconsciente, reveladoras não do pensar, mas do ser, manifestando-se, por exemplo, pelo riso espontâneo.

Mas o que fazer com ideais quando pacientes sofrem, reclamam, pioram, morrem? A exigência pautada na idealização pode ser reforçada no decorrer do curso. Algumas atitudes e situações aterrorizam os alunos e podem, em vez de transmitir e estimular a busca de conhecimentos, fazer com que jovens se endureçam, perdendo a capacidade de perceber o sujeito huma- 
no diante de si, e de perceber a si mesmos como sujeitos. O desenvolvimento do superego ${ }^{34}$, como instância sádica, pode ser estimulado pela intensidade de vivências, pela falta de suporte adequado dos professores ou da estrutura de ensino, como também em consequência da perversidade com que os alunos são eventualmente tratados por um corpo social perverso.

"Foi angustiante não deixá-la morrer, investir demais! Ela olhando, 'por favor'! Nossa, foi horrível. Gemendo, com falta de ar. Segurando minha mão, olhando." (M)

"Nada ia resolver!" (V)

"Médico não é só para melhorar, pode ajudar na morte também." (P)

"Muitas vezes o médico acaba pensando: 'ah, eu vou tentar, porque, senão, o que vão achar que eu fiz?' Fui examinar o senhor $X$, ele parou de respirar, não tinha pulso! Me apavorei: vai morrer na minha frente!" (S)

"Acompanhei uma cena, fiquei chocada:-O residente atendia uma paciente fazendo tratamento para câncer de mama, ela chegou falando: 'Ah, doutor, eu não consigo largar o cigarro e tenho consciência que não vou conseguir. De vez em quando, ainda estou bebendo.' Ele: 'Aí, a senhora sabe que tem que parar, né?' Ela: 'Ah, eu sei, mas não adianta. Eu já tomei remédios, fiz tudo e não consigo.' Ele: 'Então é mais fácil se jogar de um penhasco do que continuar assim. A senhora só volte aqui quando tiver parado de fumar e de beber.' Estava claro que ele estava frustrado, que estava querendo fazer alguma coisa, mas a paciente não estava dando retorno. Elevou o tom da voz, sabe? A mulher ficou assustada e foi embora!" (A)

Os avanços tecnológicos movimentam grandes custos financeiros, tornando a demanda da saúde como direito universal, sendo esta a grande preocupação das políticas públicas. Como definir quais os limites da ação do médico e a que ele deve responder?

Chemama e Vandermersch ${ }^{35}$ fazem uma leitura do desejo como uma falta inscrita na fala, efeito da marca do significante sobre o ser falante. Ao relacionar o desconhecimento do desejo, pelo sujeito, como causa do sintoma, Freud ${ }^{(36)}$ descobre, em suas histéricas, a conotação sexual proibida e sua articulação com a linguagem. Para Lacan ${ }^{13}$, o desejo desliza em uma cadeia significante que interdita o acesso ao objeto que o sujeito supõe perdido. Para constituir-se como sujeito desejante, é preciso simbolizar a falta primordial, angustiante vazio da condição humana, mas é nessa condição que se abrem possibilidades de dar nomes e construir objetos que sejam causa do desejo.
Os pacientes procuram os médicos com sintomas e demandas, mas sua demanda nem sempre é a cura, pois o corpo pode ficar apenas como o substrato de um gozo. Desafiando e solicitando que o tire da miserável situação de doente, o paradoxo humano tantas vezes conserva o desejo de manter seu estado enfermo nos meandros inconscientes.

A transferência está articulada ao desejo como fenômeno nodal do ser humano. Um médico que suporte a sua posição, compreenda e saiba como lidar com a transferência, consegue atender de modo mais efetivo e competente.

\begin{abstract}
"Na psico, se aprende a não ignorar o que se percebe no paciente. Ver que o paciente tá bravo, que tá mal-humorado, ou triste, e aos poucos, a gente vai vendo que é bom falar sobre isso, não tirar conclusões precipitadas das coisas, sabe? Perguntar, tentar entender e não ficar imaginando coisas e agindo sobre as nossas suposições." (GP)

"Um paciente suspirava muito. Ah, ah. Eu não sabia se era de dor, eu não sabia por que era, não sabia se tava bem, se tava com falta de ar, e ele não falava nada. E eu: 'Seu José, o senhor respira assim por quê? O senhor tá com falta de ar? Por que o senhor tá suspirando? O que há com o senhor?'. Aí ele falou: 'Eu faço assim pra puxar uma energia [risos]. Pra puxar uma coisa boa na minha vida: eu tô nessa cama e faço isso pra puxar um arco-íris, o pôr-do-sol no horizonte, um rosto bonito'. Eu pensei: 'Nunca ia ouvir isso, se não tivesse pedido...' Hoje eu tenho coragem, ver o paciente e falar: 'E esse olho cheio d'água é o quê?' Eu tenho essa liberdade, a gente tem que querer ouvir." (BA)
\end{abstract}

\section{CONSIDERAÇÕES FINAIS}

Os temas destacados durante a análise psicanalítica ligaram-se principalmente à aquisição de conhecimentos tomada como símbolo de competência profissional e ao enfrentamento das questões ligadas com a morte. Revelaram-se intensas angústias e temores gerados pela percepção que os alunos têm de suas faltas, falhas ou da incompletude de saberes em geral, culminando no temor sentido ao imaginar responsabilidades a serem enfrentadas após a formatura, quando já não haverá o apoio dos mestres para tomar decisões, particularmente em questões que ameaçam vidas. Foram fortes as referências do grupo a expectativas advindas do meio social, no sentido de ideais e exigências a serem atendidas.

Para atender, assim como para ensinar, é preciso suportar que não se sabe tudo, pois é suportando ser ferido em seu narcisismo que o médico ou o professor podem buscar alguns dos mais verdadeiros saberes. Quando servem como suporte 
ou como referência a questões éticas, os ideais do ego podem basear relacionamentos de médicos e pacientes ou de alunos e professores, propiciando a sustentação necessária para lidar com as frustrações inerentes ao trabalho médico, inevitavelmente convivendo com a morte. No entanto, exigências extremadas que tentam atender a demandas sádicas, estimulam a criação de couraças defensivas, dirigindo à impessoalização e à desumanização.

Alunos/monitores, bem como professores, ocupando essa posição em que o saber é procurado, podem dirigir ao outro a palavra como quem não sabe tudo, pois nunca se pode saber completamente e, assim, abrir o espaço para que cada um crie, ao seu próprio estilo. Desse modo, é possível tornar-se desejante de saber, assumindo as responsabilidades que acompanham o processo. Essa posição promove o desenvolvimento da transferência e suas repercussões no desenvolvimento de habilidades para a prática médica. Para que tal processo ocorra, verificou-se a importância da prática desenvolvida em pequenos grupos, possibilitando maior capacidade de comunicação, intimidade e abordagem da subjetividade. De acordo com Miller ${ }^{37}$, Lacan, em "O momento de concluir", coloca a ênfase na tecedura do aprendiz, enfatizando a aprendizagem com aqueles que nos ensinaram a língua e que nos veicularam um contexto cultural, as exigências do superego, ideais e contingências da vida.

A pessoa devia deixar-se inundar pela alegria aos pou$\cos$ - pois era vida nascendo. E quem não tivesse força de ter prazer, que antes cobrisse cada nervo com uma película protetora, com uma película de morte para poder tolerar o grande da vida ${ }^{38}(p .33)$.

Reporto-me à palavra poética de Clarice Lispector, para refletir sobre morte como aspectos imutáveis, reais e inacessíveis, trazendo a repetição inconsciente, nunca igual, e buscando simbolização através da palavra.

Defrontar-se com a complexidade de questões provocadas pelo sofrimento e morte vividos pelos estudantes de medicina ultrapassa limites toleráveis para a condição humana em sua subjetividade, exigindo medidas para o extravasamento, criação de metáforas e espaços de criação.

A capacidade de sustentar a estranheza, fazer o corte na ilusão de um saber absoluto, permite que surja a diferença de cada um. Cada paciente, cada aluno, cada situação a ser enfrentada comporta algo radicalmente único a ser encarado, convocando-nos a aprender sempre.

\section{REFERÊNCIAS}

1. Abuchaim D. Uma experiência de ensino de psicologia médica e psiquiatria. J Bras Psiquiatr. Rev Bras Educ Med. 1980;4(1):11-9.
2. Freud S. Psicanálise. In: Freud S. Edição standard brasileira das obras psicológicas completas de Sigmund Freud. Salomão J, trad. Rio de Janeiro: Imago;1980, v. XX, p. 295309.

3. Freud S. Sobre o ensino da psicanálise nas universidades. In: Freud S. Edição standard brasileira das obras psicológicas completas de Sigmund Freud. Salomão J, trad. Rio de Janeiro: Imago; 1980, v. XVII.

4. Lacan J. O saber do psicanalista. Seminário 1971-1972. Fonsêca L, trad. Recife: Centro de Estudos Freudianos do Recife; 1997.

5. Muniz JR, Chazan LF. Ensino de psicologia médica. In: Mello F, org. Psicossomática Hoje. Porto Alegre: Artes Médicas;1992. p. 37-44.

6. Zaidhaft S, Batista A, Rego G, Bines J, Rubinstein L, Drumond LE. O estudante de medicina e a morte. In: Mello F, org. Psicossomática Hoje. Porto Alegre: Artes Médicas;1992. p. 57-63

7. Nogueira-Martins LA. Saúde mental dos profissionais de saúde. Rev Bras Med Trab. 2003;1(1):56-68.

8. Gauer G, Franco R, Zogbi H, Mauni P, Diefenthabler E, Cataldo Neto A. Estratégias dos profissionais de saúde para cuidar dos que cuidam. Rev Bioét 2006;14(2):171-80.

9. Balint M. O médico, seu paciente e a doença. Rio de Janeiro: Atheneu, 1988.

10. Eksterman A. Ensino de psicologia médica. In: Mello F, org. Psicossomática Hoje. Porto Alegre: Artes Médicas;1992. p. 28-34.

11. Souza ARND. Formação médica, racionalidade e experiência: o discurso médico e o ensino da clínica. Rio de Janeiro; 1998. Doutorado [Tese] - Instituto de Psiquiatria, Universidade Federal do Rio de Janeiro. [acesso em 25 jun. 2011]. Disponível em: http://www.psy.med.br/textos/racionalidade/alicia.pdf

12. Cohen RHP. Uma questão entre psicanálise e educação: sobre a etiologia de fracasso escolar. Rio de Janeiro;2004. Doutorado [Tese] - Instituto de Psicologia, Universidade Federal do Rio de Janeiro. [acesso em 10 set. 2012]. Disponível em: http:/ / www.cfch.ufrj.br/biblioteca.php

13. Lacan J. Escritos. Ribeiro V, trad. Rio de Janeiro: Jorge Zahar;1998.

14. Folberg MN, Paim RMO. Apresentação. In: Folberg MN, Paim RMO, orgs. Educação (des)encantada. Porto Alegre: Est. Edições;2009.p. 7-10.

15. Ponte CI, Torres MA, Machado CL, Manfroi WC. A extensão universitária na Famed/UFRGS: cenário de formação profissional. Rev Bras Educ Med. 2009;33(4):527-34. 16. Manfroi WM, Machado CLB, Dorneles MA, Ribeiro EC, 
Bordin R. Estratégias para a implementação de um projeto de pós-graduação em Educação e Saúde na Faculdade de Medicina da Universidade Federal do Rio Grande do Sul. Rev Bras Educ Med [periódico na internet].2008 [acesso em 20 set. 2011]; 32(1):127-32. Disponível em: http:/ / dx.doi.org/10.1590/S0100-55022008000100017.

16. Brasil, Ministério da Saúde, Secretaria Executiva, Núcleo Técnico da Política Nacional de Humaniza SUS: Política Nacional de Humanização: a humanização como eixo norteador das práticas de atenção e gestão em todas as instâncias do SUS. 2004. [on-line] Brasília: MS;2004. [acesso em 29 abr. 2011]. Disponível em: http://bvsms. saude.gov.br/bvs/publicacoes/humanizasus_2004.pdf

17. Brasil, Ministério da Educação, Coordenação de Aperfeiçoamento de Pessoal de Nível Superior (Capes). Portaria $\mathrm{n}^{-}$9, de 23 de janeiro de 2008. [on-line]. 2008 [acesso em 30 abr. 2011]. Disponível em: http://www.capes.gov.br/ avaliacao/tabela-de-areas-de-conhecimento.

18. Deslandes SF, Mitre RMA. Processo comunicativo e humanização em saúde. Interface Comun Saúde Educ. 2009;13(supl 1):641-9.

19. Rego S, Gomes AP, Siqueira-Batista R. Bioética e humanização como temas transversais na formação médica. Rev Bras Educ Med. 2008;32(4):482-91.

20. Lampert JL. Tendências de mudanças da formação médica no Brasil [online]. Rio de Janeiro; 2002. Doutorado [Tese] Fundação Oswaldo Cruz. [acesso em 2 maio 2011]. Disponível em: http:/ / teses.icict.fiocruz.br/pdf/lampertjbd.pdf

21. Berbel NAN. Metodologia da problematização no ensino superior e sua contribuição para o plano da praxis. Semina. 1999; 17:7-17.

22. Freire, P. Extensão ou comunicação? Rio de Janeiro: Paz e Terra; 1977.

23. Eizirik CL. Ensinando uma profissão impossível. Rev ABP-APAL. 1994;16(4): 133-5.

24. Bertoldi SG. Relação médico-paciente em estudantes de medicina. Atividade de Extensão - Pró-Reitoria de Extensão e Cultura, Universidade Federal de Pelotas. Pelotas; 2009. [Código DIPLAN/PREC: 52546019.]

25. Bertoldi SG, Braga FB. Psicanalistas na universidade. O que se pode fazer? Anais do II Congresso Luso-Brasileiro de Psicanálise; 2007 nov 15-16; Salvador, Brasil. [acesso em 29 jan. 2011]. Disponível em: http:/ / febrapsi.org.br/publicacoes.php\#.

26. Brasil, Ministério da Saúde, Conselho Nacional de Saúde, Comissão de Ética. Resolução nº196, de 10 de outubro de 1996. Institui diretrizes e normas regulamentadoras de pesquisa envolvendo seres humanos. Brasília; 1996.
27. Lüdke M, Meda A. Pesquisa em educação: abordagens qualitativas. São Paulo: EPU; 1986.

28. Yin RK. Estudo de caso: planejamento e métodos. $3^{\text {a }}$ ed. Porto Alegre: Bookman; 2005.

29. Minayo MCS. O desafio do conhecimento: pesquisa qualitativa em saúde. 9aㅡ ed. São Paulo: Hucitec, 2006.

30. Schüller D. Mito, uma espécie de sonho coletivo. In: Folberg MN, Paim RMO, org. Educação des(encantada). Porto Alegre: Est. Edições; 2009. p. 13-38.

31. Lacan J. Meu ensino. Telles A, trad. Rio de Janeiro: Jorge Zahar;2006.

32. Roudinesco EPM. Dicionário de Psicanálise. Magalhães L, Ribeiro V, trad. Rio de Janeiro: Jorge Zahar; 1998. A posteriori; p. 32.

33. Freud S. O ego e o superego (ideal do ego). In: Freud S. Edição standard brasileira das obras psicológicas completas de Sigmund Freud. Salomão J, trad. Rio de Janeiro: Imago; 1980, vol. XIX, p 42-54.

34. Chemama R, Vandermersch B. Dicionário de Psicanálise. Settineri F, Fleig M, trad. São Leopoldo: Unisinos; 2007. Desejo; p. 89

35. Freud S. A sexualidade na etiologia das neuroses. In: Freud S. Edição standard brasileira das obras psicológicas completas de Sigmund Freud. Salomão J, trad. Rio de Janeiro: Imago; 1980, p. 285-312.

36. Miller JA. Perspectivas do Seminário 23 de Lacan: o sinthoma. Prado T, trad. Rio de Janeiro: Jorge Zahar; 2009. p. 193.

37. Lispector C. Aprendendo a viver. Rio de Janeiro: Rocco; 2005.

\section{CONTRIBUIÇÃO DOS AUTORES}

Sandra Gehling Bertoldi participou da concepção e desenho do estudo, da aquisição de dados, de sua análise, da elaboração do artigo e sua aprovação final. Maria Nestrovski Folberg e Waldomiro Carlos Manfroi fizeram contribuições substanciais para a concepção e desenho do estudo, análise e interpretação dos dados, na revisão crítica do artigo e em sua aprovação final.

\section{CONFLITO DE INTERESSES}

Declarou não haver.

\section{ENDEREÇO PARA CORRESPONDÊNCIA}

Sandra Gehling Bertoldi

Rua Dr.Víctor Russomano, 47

Bairro - Pelotas

CEP 96077620 RS

E-mail: sandrabertoldi@yahoo.com.br 